\title{
IDENTIFICACIÓN MEDIANTE PCR DEL SEXO DE LA PAPAYA (Carica papaya L.), HÍBRIDO "POCOCÍ"1
}

\author{
Ericka Saalau-Rojas', Walter Barrantes-Santamaría ${ }^{3}$,Carlos Luis Loría-Quirós ${ }^{3}$,Arturo Brenes-Angulo², \\ Luis Gómez-Alpízar ${ }^{2}$
}

\begin{abstract}
RESUMEN
Identificación mediante PCR del sexo de la papaya (Carica papaya L.), híbrido “Pococí". El objetivo de la presente investigación fue identificar plantas hermafroditas del híbrido de papaya "Pococí". Para la identificación del sexo de las plantas del híbrido "Pococí", se utilizó el protocolo descrito por Deputy et al. (2002), con algunas modificaciones. Esta metodología emplea un PCR múltiple que permite la amplificación simultánea de dos fragmentos (1.300 y 800 $\mathrm{pb}$ respectivamente) para plantas hermafroditas y de un solo fragmento $(1.300 \mathrm{pb})$ para plantas femeninas. El ADN se extrajo a partir de hojas de plantas de invernadero o campo con dos metodologías de extracción, CTAB y lisis alcalina $(\mathrm{NaOH})$. La amplificación por PCR del ADN extraído de muestras foliares de papaya híbrido "Pococî", con ambos métodos de extracción, produjo los fragmentos del tamaño esperado. La determinación del sexo de 1.500 plántulas en almácigo mostró un $46 \%$ de plántulas hermafroditas y un 54 $\%$ de plantas femeninas. La proporción observada de plantas femeninas: hemafroditas no varió de la esperada (1:1) según la prueba de chi-cuadrado $(\mathrm{p}=0,4237)$. Las plantas hermafroditas fueron llevadas al campo y al momento de la floración se determinó su sexo. La correspondencia entre el sexado por PCR y la expresión sexual en campo fue de un $98 \%$.
\end{abstract}

Palabras clave: Plantas hembra, hermafroditas, marcadores moleculares, extracción de ADN, genes ligados al sexo.

\begin{abstract}
Sex determination of papaya (Carica papaya L.) "Pococi" hybrid by PCR. The objective of this work was to identify papaya hermaphrodite plants of the hybrid "Pococí" at the seedling stage using the Polymerase Chain Reaction (PCR). Sex identification was achieved according to the methodology described by Deputy et al. (2002) with some modifications. This methodology employs a multiplexPCR assay that allows simultaneous amplification of two fragments ( $800 \mathrm{bp}$ and 1300 respectively) for hermaphrodite plants and one fragment (1300 bp) for female plants. Genomic DNA was extracted from leaves and two extraction protocols were evaluated, CTAB and rapid alkaline lysis $(\mathrm{NaOH})$. The amplification reaction yielded the expected size of the fragments with both methods of DNA extraction. PCR sex determination of 1500 seedlings yielded $46 \%$ of hermaphrodite and $54 \%$ of female plants. The female: hermaphrodite plant ratio observed did not vary from the expected (1:1) ratio according to the chi-square test ( $\mathrm{p}=$ 0.4237). Hermaphrodite plants were planted in the field in San Carlos region, Costa Rica, and sex was determined at flowering. The correspondence between the PCR sexed plants and sexual expression in the field was $98 \%$.
\end{abstract}

Key words: Female plants, hermaphrodites, molecular markers, DNA extraction, sex-linked genes, sex expression.

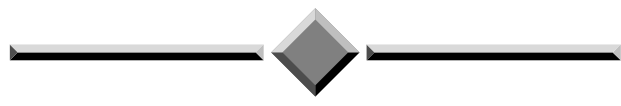

\footnotetext{
1 Recibido: 16 de marzo, 2009. Aceptado: 16 de noviembre, 2009. Proyecto de investigación "Innovación tecnológica en almacigos de papaya" de la Universidad de Costa Rica.

2 Laboratorio de Biotecnología de Plantas, Centro de Investigaciones Agronómicas, Universidad de Costa Rica. San José, Costa Rica. esaalau@gmail.com, arturo.brenes@ucr.ac.cr, luis.gomezalpizar@ucr.ac.cr

3 Estación Experimental Agrícola Fabio Baudrit Moreno, Universidad de Costa Rica. Alajuela, Costa Rica. walter.barrantes@ucr.ac.cr, clloria@gmail.com.
} 


\section{INTRODUCCIÓN}

La papaya presenta tres tipos de plantas de acuerdo al sexo de las flores que produce: hembras, machos y hermafroditas. Diferentes hipótesis han sido planteadas para explicar la genética de la determinación del sexo en papaya, incluyendo el control por un solo gen con al menos tres alelos, el control por dos genes diferentes, un grupo de genes fuertemente ligados, la presencia de un sistema de cromosomas XY, balance génico de cromosomas sexuales sobre autosomas, elementos reguladores de la vía de desarrollo floral y el control ejercido por dos cromosomas Y levemente diferentes (Y y Y ${ }^{\mathrm{h}}$ ) (Hofmeyr 1938, Storey 1938, 1953 y 1976, Sondur et al. 1996, Gaurab et al. 2007, Ming Yu y Moore 2007, Qingyi et al. 2008).

Las plantas con flores hermafroditas son las que producen frutos con las mejores características comerciales: forma alargada y piel gruesa, lo cual les permite resistir más los daños mecánicos en poscosecha y una cavidad interna pequeña, es decir una mayor relación pulpa/semillas (Chaves y Nuñez 2007, Mora y Bogantes 2005). Sin embargo, el sexo de las plantas de papaya solo puede ser determinado hasta que las plantas llegan a la floración (de dos a tres meses). Por lo tanto, para obtener una plantación con plantas mayoritariamente hermafroditas, el productor debe sembrar de tres a cuatro plantas por punto de siembra y eliminar al momento de la floración los fenotipos no deseados (machos y hembras). Esta práctica resulta en un aumento de los costos de producción como consecuencia del mayor número de plántulas sembradas y el mantenimiento de las mismas hasta el momento de ser removidas. Además, requiere de personal capacitado que conozca bien la morfología floral de la papaya y sepa distinguir las flores hermadrofitas de las femeninas. Por otro lado, existe siempre el inconveniente de obtener frutas con un menor valor comercial, ya que no siempre se elimina certeramente los genotipos indeseables y la constitución final de la plantación es de un 92 a un $94 \%$ de plantas hermafroditas solamente, y no del $100 \%$ deseado (Mora y Bogantes 2005).

La determinación del sexo de plantas de papaya en etapas tempranas de su desarrollo permite el ahorro de recursos, al facilitar la siembra de plantas $100 \%$ hermafroditas (Parasnis et al. 1999). Diferentes estudios han sido conducidos para el establecimiento de un sistema temprano para la determinación del sexo en papaya. Los mismos incluyen análisis morfológicos, citológicos, isoenzimáticos y de contenido de fenoles (Magdalita y Mercado 2003). Hasta la fecha, ninguno de estos métodos permite determinar el sexo de las plantas de papaya en el estado de plántula o semilla. La mayoría de los sistemas evaluados distinguen plantas hembra de plantas macho pero no de plantas hermafroditas y no son aptos para el análisis de grandes grupos de muestras. Esto ha generado interés por desarrollar estrategias de identificación del sexo en papaya a través de marcadores moleculares, particularmente mediante la aplicación de técnicas basadas en la reacción en cadena de la polimerasa o PCR (por sus siglas en inglés). Varios autores han diseñado iniciadores de PCR a partir de marcadores moleculares que permiten el diagnóstico del sexo de plantas de papaya en estados tempranos de desarrollo (Gill et al. 1998, Parasnis et al. 2000, Deputy et al. 2002, Urasaki et al. 2002 a, b, Chaves y Nuñez 2007). Normalmente, el diseño de los imprimadores se basa en la determinación de marcadores RAPDs (Fragmentos polimórficos de ADN Amplificados al Azar) asociados a un tipo sexual. Luego los fragmentos se clonan y se secuencian para generar SCARs (Secuencias Caracterizadas Amplificadas al Azar), y finalmente se emplean las secuencias para diseñar los imprimadores que permiten la amplificación mediante PCR de fragmentos específicos para el tipo sexual. Por lo general es posible distinguir plantas hembra de hermafroditas y masculinas; pero no plantas hermafroditas de masculinas (Deputy et al. 2002, Urasaki et al. 2002 a,b, Chaves y Nuñez 2007).

El método descrito por Deputy et al. (2002) es particularmente útil ya que emplea un PCR múltiple que permite la amplificación simultánea de dos fragmentos (1.300 y $800 \mathrm{pb}$ respectivamente) en plantas hermafrodita y de un solo fragmento $(1.300 \mathrm{pb})$ en plantas femeninas. El fragmento de 1.300 pb es común a ambos sexos, lo que sirve como control interno de la amplificación, obviando los falsos negativos que se presentan en los sistemas que utilizan presencia y ausencia de una sola banda (PCR simple) para la determinación del sexo. La presencia de la banda indica que la planta es femenina y la ausencia que es hermafrodita o viceversa. De manera que si el ADN extraído no es amplificable podrían obtenerse falsos negativos. La ausencia del producto de PCR se debe no a que la planta sea femenina o hermafrodita, sino a que la cantidad o calidad del ADN no fue apropiada para su 
amplificación, lo que se obvia con el PCR múltiple (Urasaki et al. 2002b).

La aplicabilidad del método de Deputy et al. (2002) para la determinación del sexo de plantas de papaya de diferentes genotipos ha sido demostrada en Hawai (Deputy et al. 2002) y Filipinas (Magdalita y Mercado 2003). Sin embargo, en Colombia, Chaves y Nuñez (2007) indicaron que el uso de imprimadores de PCR desarrollados a partir de genotipos de papaya de otras localidades falló cuando se aplicaron a genotipos locales y concluyeron que es necesario validar los métodos de sexado de plantas con los materiales locales. En el híbrido "Pococí" la población resultante sigue una relación 1:1 femeninas-hermafroditas. Los machos están ausentes, lo que abre la posibilidad de emplear el método de Deputy et al. (2002) para diferenciar entre plantas hermafroditas y hembras de este híbrido en etapas tempranas del desarrollo de las plantas.

El presente trabajo tuvo como objetivos: 1) validar el método de Deputy et al. (2002) para la determinación de sexo en plantas de papaya del híbrido "Pococî"; 2) comparar dos métodos de extracción de ADN, CTAB (Rogers y Bendlich 1988) y NaOH (GE Healthcare 2005), con el propósito de disminuir el tiempo necesario para procesar una muestra y 3 ) establecer la concordancia entre la determinación del sexo por PCR y la morfología floral.

\section{MATERIALES Y MÉTODOS}

\section{Material vegetal}

Se recolectaron hojas de 1500 plántulas de invernadero de tres semanas de edad y de 146 plantas en estado de prefloración en el campo del híbrido "Pococí”. Ambos materiales provinieron de la Estación Experimental Agrícola Fabio Baudrit Moreno (EEFBM) en Alajuela, Costa Rica en el año 2007.

La extracción de ADN se efectuó en el Centro de Investigaciones Agronómicas (CIA).

\section{Extracción del ADN con CTAB}

Para la extracción de ADN con CTAB (bromuro de cetril-trimetil amonio) se siguió el método descrito por Rogers y Bendlich (1988), con algunas modificaciones.
Secciones de hoja de $1 \mathrm{~cm}^{2}$ de tamaño se colocaron en un tubo Eppendorf plástico de 1,5 ml. Luego se agregó nitrógeno líquido y se maceró el tejido con la ayuda de un taladro manual al que se le colocó un pistilo plástico. $\mathrm{Al}$ macerado resultante se adicionaron $300 \mu \mathrm{l}$ de amortiguador de extracción CTAB (CTAB $2 \%$, Tris- $\mathrm{HCl}$ $0.2 \mathrm{M}, 0.05 \mathrm{M}$ EDTA, $2.0 \mathrm{M} \mathrm{NaCl}$ ) y la mezcla se incubó a $65{ }^{\circ} \mathrm{C}$ por $30 \mathrm{~min}$. Posteriormente se agregaron 300 $\mu \mathrm{L}$ de cloroformo-fenol-alcohol isoamílico (25:24:1) y se mezcló suavemente por inversión. Para separar las fases se centrifugó a $12.000 \mathrm{rpm}$ durante $15 \mathrm{~min}$ y se transfirió la fase acuosa a un nuevo tubo Eppendorf. Se repitió la extracción orgánica con cloroformo-fenol-alcohol isoamílico y se recuperó la fase acuosa, a la que se le agregaron $20 \mu \mathrm{l}$ de $\mathrm{NaOAc} 3,0 \mathrm{M}(\mathrm{pH} 5,2)$ y 300 $\mu \mathrm{l}$ de isopropanol frío, para la precipitación del ADN. La mezcla se dejó reposar a $-20{ }^{\circ} \mathrm{C}$ durante la noche. Luego se centrifugó por 15 min a 13.000 rpm y se eliminó el sobrenadante. El precipitado se lavó dos veces con $70 \mu \mathrm{l}$ de etanol frío al $70 \%$ y se centrifugó durante 5 min (cada vez) a $13.000 \mathrm{rpm}$. El precipitado final se secó en una cámara de flujo laminar y se rehidrató en $40 \mu \mathrm{L}$ de agua doble destilada-doble autoclavada. Posteriormente se preparó una dilución 1:10 en agua para su uso en PCR. La calidad y rendimiento del ADN genómico se determinó en un gel de agarosa al $1 \%$ corrido en TBE $0.5 \mathrm{X}$ (Tris $10 \mathrm{mM}$, Borato $20 \mathrm{mM}$, EDTA $1,0 \mathrm{mM})$ y teñido con bromuro de etidio.

\section{Extracción de ADN con $\mathrm{NaOH}$}

$\mathrm{Al}$ igual que en el método anterior, se colocaron secciones de hoja de $1 \mathrm{~cm}^{2}$ en tubos Eppendorf plásticos de 1,5 ml. Según la metodología descrita por GE Healthcare (2005), se agregaron $150 \mu 1 \mathrm{de} \mathrm{NaOH} 0,25$ M con $0,1 \%$ Tween $20 \mathrm{v} / \mathrm{v}$ a cada tubo y se maceró cada muestra con la ayuda de un taladro manual al que se le colocó un pistilo plástico. Al macerado resultante se adicionaron $150 \mu \mathrm{l}$ de solución neutralizadora (80 $\mathrm{mM}$ Tris- $\mathrm{HCl}, \mathrm{pH} 8,0,1,0 \mathrm{mM}$ EDTA) y la mezcla se incubó a $70{ }^{\circ} \mathrm{C}$ durante $30 \mathrm{~min}$. Para separar las fases se centrifugó a $12.000 \mathrm{rpm}$ durante 15 minutos y se transfirió la fase acuosa a un nuevo tubo. Esta se diluyó en agua en una relación 1:25 para su uso en el PCR. La calidad y rendimiento del ADN genómico extraído se determinó de la misma manera que con el método de extracción CTAB. 


\section{Determinación del sexo mediante PCR}

La reacción de amplificación por PCR del ADN extraído de muestras foliares de plantas de papaya híbrido "Pococí" provenientes de invernadero y campo, con ambas metodologías de extracción, se realizó de acuerdo al protocolo descrito por Deputy et al. (2002). Se emplearon los imprimadores W11-F (CTGATGGCGTGTGTGGCTCTA), W11-R (CTGATGCGTGATCATCTACT), T1-F (TGCTCTTGATATGCTCTCTG) y T1-R (TACCTTCGCTCACCTCTGCA) en una reacción de PCR múltiple. La reacción fue llevada a cabo en un volumen total de $25 \mu \mathrm{l}$ con una concentración final de $1 \mathrm{X}$ de amortiguador de reacción de PCR (Tris- $\mathrm{HCl} 75 \mathrm{mM} \mathrm{pH} \mathrm{8,8;} \mathrm{(NH4)})_{2} \mathrm{SO}_{4} 20 \mathrm{mM}$ y 0,01 $\%$ de gelatina), $1,7 \mathrm{mM} \mathrm{MgCl}, 0,16 \mathrm{mM}$ dNTP, 0,18 $\mu \mathrm{M}$ de cada imprimador, $0,8 \mathrm{mg} / \mathrm{ml} \mathrm{BSA}$, una unidad de Taq ADN polimerasa y $4 \mu \mathrm{l}$ de una dilución $1 / 10$ de ADN para muestras procesadas con el protocolo de extracción de CTAB y de 1:25 para aquellas con el protocolo de $\mathrm{NaOH}$ (aproximadamente entre 10 y $50 \mathrm{ng}$ de ADN). Los reactivos utilizados fueron de la marca comercial Fermentas UAB, Life Sciences, Lithuania. Las amplificaciones se realizaron en un termociclador Perkin Elmer GeneAmp PCR System 2.400 y consistieron de una desnaturalización inicial a $95{ }^{\circ} \mathrm{C}$ por tres minutos, seguida por 30 ciclos de $95{ }^{\circ} \mathrm{C}$ por un min, $58{ }^{\circ} \mathrm{C}$ por un minuto, $72{ }^{\circ} \mathrm{C}$ por dos minutos y un período final de extensión a $72{ }^{\circ} \mathrm{C}$ por siete minutos. Los productos de la reacción de amplificación fueron visualizados en geles de agarosa al 1,6\% peso/volumen preparados en 0,5X TBE (Tris $10 \mathrm{mM}$, Borato $20 \mathrm{mM}$; EDTA $1,0 \mathrm{mM}$ ) suplementados con $1 \mu \mathrm{l}$ de bromuro de etidio $(10 \mathrm{mg} / \mathrm{ml})$. La electroforesis se realizó a 70 V durante 1,5 horas. Las bandas se observaron con luz UV en un transiluminador Kodak EDAS 290.

\section{Evaluación en campo de las plantas hermafroditas sexadas}

Una vez sexadas, se trasplantaron a campo 360 plántulas hermafroditas en la zona de San Carlos, Alajuela. El manejo agronómico de las plantas fue el utilizado por el productor en su plantación. Al momento de la floración, aproximadamente dos meses después de la siembra, se determinó morfológicamente el sexo de cada una de las plantas establecidas en el campo.

Los datos totales de sexado por PCR se sometieron a una prueba de chi-cuadrado para determinar si la relación hermafroditas:hembras determinada correspondía a la proporción 1:1 esperada para el híbrido "Pococí".

\section{RESULTADOS}

El ADN extraído con ambos métodos, CTAB y $\mathrm{NaOH}$, resultó adecuado para su amplificación mediante PCR. Cada muestra presentó el mismo patrón de bandas, independiente del método de extracción (Figura 1). La reacción de amplificación produjo los fragmentos del tamaño esperado, $1.300 \mathrm{pb}$ para la combinación de imprimadores T1-F y T1-R y 800 pb para la combinación W11-F/W11-R. Las plantas hermafroditas presentaron el patrón de dos bandas, 1.300 y $800 \mathrm{pb}$ respectivamente; mientras que en las plantas hembra un patrón de una sola banda de $800 \mathrm{pb}$, independientemente del estado de desarrollo: plántulas de invernadero (Figura 2a) o en prefloración en campo (Figura 2b). La aplicación de la técnica de PCR para la determinación del sexo de 145 plantas de papaya de sexo conocido provenientes del campo, mostró una coincidencia del $96 \%$ entre PCR y la morfología floral (Cuadro 1).

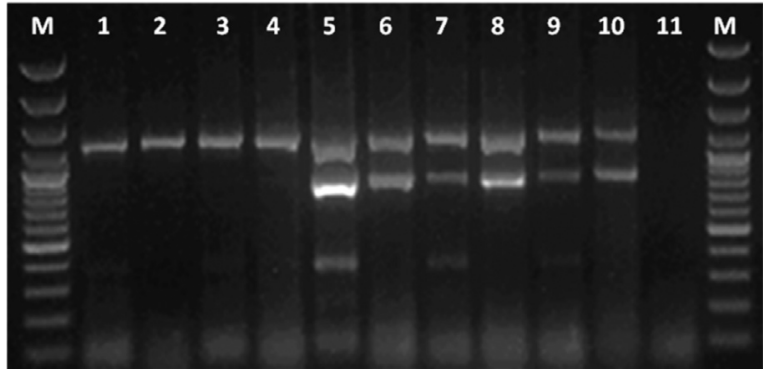

Figura 1. Productos de PCR obtenidos a partir de ADN extraído de hojas de papaya del híbrido "Pococí" de plantas de invernadero, mediante los métodos de lisis alcalina $\mathrm{NaOH}$ (celdas $1,3,5,7,9)$ y CTAB (celdas 2, 4, 6, 8, 10. Patrón de doble banda corresponde a plantas hermafroditas, patrón de una banda a plantas femeninas. Celda 11, control negativo sin $\mathrm{ADN}$. $\mathrm{M}=$ Marcador molecular de 100 bp. Centro de Investigaciones Agronómicas (CIA). San José, Costa Rica. 2007.

Debido a que la metodología de extracción con $\mathrm{NaOH}$ resulta más barata y es más rápida, se procedió 


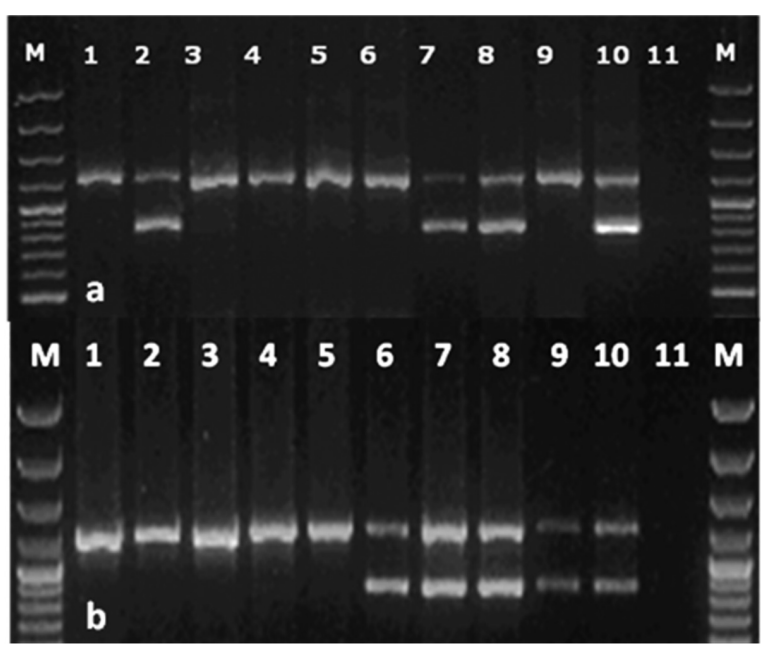

Figura 2. Amplificación por PCR múltiple del ADN extraído de muestras foliares de plántulas de invernadero de tres semanas de edad (a) y plantas de campo (b) del híbrido "Pococí". Patrón de doble banda corresponde a plantas hermafroditas, patrón de una banda a plantas femeninas. Celda 11, control negativo sin $\mathrm{ADN}, \mathrm{M}=$ Marcador molecular de 100bp. Centro de Investigaciones Agronómicas (CIA). San José, Costa Rica. 2007.

Cuadro 1. Determinación de sexo en plantas de papaya del híbrido Pococí, mediante PCR y morfología floral (145 muestras evaluadas). San José, Costa Rica. 2007.

\begin{tabular}{lcc}
\hline \multicolumn{1}{c}{ Tipo de planta } & PCR & Morfología floral \\
\hline Hermafroditas & 82 & 77 \\
Femeninas & 63 & 68 \\
\hline
\end{tabular}

a extraer el ADN de muestras foliares de plántulas en invernadero $(\mathrm{n}=1.500)$ con esta metodología. Posteriormente se procedió a determinar su sexo mediante el PCR múltiple (Figura 2a). Un $46 \%$ de las plántulas resultaron hermafroditas y un $54 \%$ hembras. Esta proporción no varió significativamente de la relación 1:1 esperada, según la prueba de chi-cuadrado $(p=$ 0,4237).

Las plantas hermafroditas fueron llevadas a campo donde al momento de la floración se determinó su sexo. La correspondencia entre el sexado por PCR y la expresión sexual en campo fue de un $98 \%$.

\section{DISCUSIÓN}

La técnica de PCR para la determinación de sexo en papaya con imprimadores derivados de marcadores RAPDs ligados al gen Sex 1 (Deputy et al. 2002), permitió la diferenciación de plantas hermafroditas y hembras del híbrido "Pococí", mejorado en Costa Rica. Estos resultados coinciden con los obtenidos en Hawai (Deputy et al. 2002) y en Filipinas (Magdalita y Mercado 2003). En Colombia, sin embargo, Chaves y Nuñez (2007) indicaron que el método no fue aplicable a los genotipos de papaya cultivados en ese país.

Las condiciones de PCR y la calidad de reactivos influyen en la amplificación por PCR de las diferentes regiones del ADN, lo que podría explicar la falta de producto de PCR cuando se empleó el ADN de los genotipos colombianos. En adición, las condiciones óptimas para realizar la amplificación varían de acuerdo a la calidad y cantidad del ADN, es decir, están relacionadas con el método de extracción del ADN. Alternativamente, diferencias genéticas (en la secuencia del ADN) entre los materiales colombianos y los empleados por Deputy et al (2002), en la región de unión de los imprimadores utilizados para PCR, harían que los iniciadores no funcionaran con los primeros materiales. Deputy et al (2002) emplearon materiales hawaianos en su trabajo original. El padre del híbrido "Pococí" es de ascendencia hawaiana del grupo "Solo" (Mora y Bogantes 1999-2002), de manera que existe una relación genética entre el híbrido "Pococí" y los genotipos hawaianos. Los cultivares hawaianos son genéticamente muy similares (Stiles et al. 1993). Deputy et al. (2002) y Magdalita y Mercado (2003), sin embargo, aplicaron con éxito el método de sexado a plantas de papaya de diferentes acervos genéticos.

Ambos métodos de extracción de ADN evaluados permitieron la obtención de ADN de papaya amplificable mediante PCR. El método de lisis alcalina con $\mathrm{NaOH}$ presentó varias ventajas sobre el método con CTAB, entre ellas fácil implementación e inocuidad, pues no utiliza reactivos corrosivos ni peligrosos para la salud como el fenol y el cloroformo, bajo costo y rapidez ya que se necesita de solamente 30 minutos en comparación con un mínimo de dos horas para el método con CTAB. Esto representa un ahorro sustancial de tiempo en la preparación de las muestras y facilita su procesamiento a gran escala. Ventajas que han sido 
previamente señaladas por otros autores (Mathias et al. 2007, De Jesús et al. 2005).

La coincidencia entre la predicción del sexo por PCR y por morfología floral fue entre un $96 \%$ y un $98 \%$, independientemente del estado de desarrollo de las plantas de papaya (plantas adultas o plántulas). Esto confirma que la técnica permite determinar el sexo de las plantas en estados tempranos del desarrollo (tres semanas de edad) y sería útil para establecer plantaciones comerciales con solo plantas hermafroditas, particularmente cuando la producción se destina a la exportación.

La utilización de técnicas moleculares representa un costo directo para los productores y para quienes se dedican a la producción de almácigos de papaya. Su implementación dentro del sistema de producción comercial de papaya dependerá de la relación costo/beneficio resultante de establecer plantaciones con mayores rendimientos comerciales (solo hermafroditas) en relación a la reducción de los costos indirectos, como la inversión de recursos y tiempo para el mantenimiento de plantas hembra no deseadas.

La técnica de PCR empleada para la determinación de sexo en papaya tiene también aplicación dentro de los programas de mejora genética del cultivo, para la determinación del sexo de las líneas utilizadas como padres en los cruzamientos para la obtención de híbridos y en la micropropagación, para evaluar la estabilidad de las líneas hermafroditas producidas mediante esta técnica.

En conclusión, la técnica de PCR validada para identificar el sexo de plantas de papaya en estados tempranos de su desarrollo, podría ser una herramienta efectiva para planificar la producción de la fruta y obtener mayor productividad por área. Su uso en la producción comercial depende de que sea costo/efectiva.

\section{LITERATURA CITADA}

Chaves-Bedoya, G; Nuñez, V. 2007. A SCAR marker for the sex determination in Colombian genotypes of Carica papaya. Euphytica 153:215-220.

De Jesús, R; Moreno, N; Martínez, J. 2005. Ensayo de dos métodos de extracción de ADN de ratón para ser usado en el control genético de ratones consanguíneos mediante la reacción en cadena de la polimerasa (PCR). Revista Científica, FCV-LUZ 15(2):134-140.

Deputy, JC; Ming R; Ma, H; Fitch, MMM; Wang, M; Manshardt, R; Shles, JI. 2002 Molecular markers for sex determinations in papaya (Carica papaya L.) Theoretical and Applied Genetics 106:107-111.

Gaurab, G; Subhash, K; Kaushik, G; Ramit, P; Bandyopadhyay, T; Debabrata, B; Mukherjee K. 2007. Sex detection of Carica papaya and Cycas circinalis in pre-flowering stage by ISSR and RAPD. Current Science 92(4):524-526.

GE Healthcare 2005. Amplification of plant DNA with Genomiphi DNA amplification kit. Nucleic acid amplification and analysis. Application note 63-005620 AA. Consultado: 30 nov. 2006. Disponible en: http://www5.gelifesciences.com/applic/upp00738.nsf/ vLookupDoc/295437086-C534/\$file/63005620.pdf.

Gill, G; Harvey, R; Gardner, R; Fraser, L. 1998. Development of sex-linked PCR marker for gender identification in Actinidia. Theoretical and Applied Genetics 97:439-445.

Hofmeyr, JDJ. 1938. Genetical studies of Carica papaya L. I. The inheritance and relation of sex and certain plant characteristics. II Sex reversal and sex forms. South African Department of Agriculture on Science Bulletin No. 187. 64 p.

Magdalita, PM; Mercado, CP. 2003. Determination the sex of papaya for improved produced. Bull. Food Fert. Tech. Centre, Philippines, 1-12. Consultado: 30 agosto 2007. Disponible en: http://ww.agnet.org/library/article/eb534html

Mathias, M; Sagredo, B; Kalazich, J. 2007. Uso de marcadores SSR para identificación de germoplasma de papa en el programa de mejoramiento de INIA de Chile. Agricultura Técnica (Chile) 67(1):3-15.

Ming, R; Yu, Q; Moore, PH. 2007. Sex determination in papaya. Seminars in Cell and Developmental Biology 18:401-408.

Mishra, M; Ramesh, C; Sangeeta, S. 2007. Papaya. In: Genome mapping and molecular breeding in plants, Volume 4. Fruits and Nuts. C. Kole. ed. Springer-Verlag Berlin Heidelberg. 370 p.

Mora, E; Bogantes, A. 1999-2002. Evaluación del potencial comercial de líneas S2 de papaya (Carica papaya L.) en la Región Atlántica de Costa Rica. Revista de Agricultura Tropical 32:73-80.

Mora, E; Bogantes, A. 2004. Evaluación de híbridos de papaya (Carica papaya L.) en Pococí, Limón, Costa Rica. Agronomía Mesoamericana 15(1):39-44.

Mora, E; Bogantes, AA. 2005 Estudio de una mutación en papaya (Carica papaya L.) que produce la letalidad de plantas femeninas. Agronomía Mesoamericana 16: 89-94. 
Parasnis, A; Ramakrishna, W; Chowdari, K; Grupta, V; Ranjekar, P. 1999. Microsatellite (GATA)n reversal sex-specific differences in papaya. Theoretical and Applied Genetics 99:1047-1052.

Parasnis, AS; Gupta, VS; Tamhankar, SA; Ranjekar, PK. 2000. A highly reliable sex diagnostic PCR assay for mass screening of papaya seedlings. Molecular Breeding 6:337-344.

Qingyi, Yu; Navajas-Pérez, R; Tong, E; Robertson J; Moore, P; Paterson A; Ming, R. 2008. Recent origin of dioecious and gynodioecious $\mathrm{Y}$ chromosomes in papaya. Tropical Plant Biology 1:49-57.

Rogers, SO; Bendich, AJ. 1988. Extraction of DNA from plant tissues. Plant Molecular Biology Manual A6:110.

Sondur, SN; Manshardt, RM; Stiles, JI. 1996. A genetic linkage map of papaya based on randomly amplified polymorphic DNA markers. Theoretical and Applied Genetics 93:547-553.

Stiles, JI; Lemme, C; Sondur, S; Morshidi, MB; Manshardt, R. 1993. Using randomly amplified polymorphic DNA for evaluating genetic relationships among papaya cultivars. Theoretical and Applied Genetics 85:697701.

Storey, WB. 1938. Segregation of sex types in Solo papaya and their application to the selection of seed. Am. Soc. Hort. Sci. Pro. 35:83-85.

Storey, WB. 1953. Genetics of papaya. J.Hered. 44:70-78.

Storey, WB. 1976. Papaya. Evolution of crop plants. Longman, San Francisco. p. 21-24.

Urasaki, N; Tokumoto, M; Tarora, K; Ban, Y; Kayano, T; Tanaka, H; Oku, H; Chinen, I; Terauchi, R. 2002a. A male and hermaphrodite specific RAPD marker for papaya (Carica papaya L.). Theoretical and Applied Genetics 104:281-285.

Urasaki, N; Tarora, K; Uehara, T; Chinen, I; Terauchi, R; Tokumoto, M. 2002b. Rapid and highly reliable sex diagnostic PCR assay for papaya (Carica papaya L.). Breeding Science 52:333-335.

Van Droogenbroeck, B; Breyne, P; Goetghebeur, P; Romeijn-Peeters, E; Kyndt, T; Gheysen, G. 2002. AFLP analysis of genetic relationships among papaya and its wild relatives (caricaceas) from Ecuador. Theoretical and Applied Genetics 105:289-297. 
